\title{
Outcome of Infants at Risk of Brain Damage after Katona Neurohabilitation Therapy
}

\section{Thalía Harmony}

Universidad Nacional Autonoma de Mexico, Instituto de Neurobiología, Querétaro, Mexico

\author{
Abstract \\ Objective: To evaluate Katona's neurohabilitation therapy in preterm and term infants with risk factors for brain \\ damage followed up to 24 months of age.
}

Methods: 262 infants from 25 to 40 weeks of gestational age (GA) were treated with neurohabilitation beginning before 2 months of corrected age. Treatment was intensive, sustained for at least 12 months and required family participation. Neuropediatric examinations, MRI and Bayley-II scales were performed.

Results: Abnormal MRI findings were observed in $80 \%$ of infants (increase in lateral ventricle volumes, decrease in corpus callosum volume, diffuse and cystic periventricular leukomalacia, diffuse white matter abnormalities, haemorrhages, infarcts).

Outcome: Bayley-II scales showed that $20 \%$ of infants with a GA of less than 29 weeks and less than $15 \%$ of infants with a 30-40 week GA had significantly delayed MDI and PDI scores.

Conclusion: Diagnosis and treatment using neurohabilitation in new-borns at risk of brain damage is recommended.

Keywords: Preterm; White matter injury; Periventricular leukomalacia; Perinatal brain damage; Low weight at birth; Physiotherapy

\section{Introduction}

Preterm birth rates have increased, even in developed countries $[1,2]$. Moderate preterm (MPT, GA=32-33 weeks) and late preterm (LPT, GA=34-36 weeks) deliveries and, to a lesser extent, early-term deliveries $(\mathrm{GA}<32$ weeks) represent a major and growing public health concern. In recent years, survival of preterm new-borns has increased due to advanced medical procedures; however, this has resulted in a rising number of infants with long-term developmental problems. Every year in France almost 35,000 babies (4-4.5\%) are born at 35-36 weeks, $13,000(1.5 \%)$ at $32-34$ weeks and $13,000(1.5 \%)$ at less than 32 weeks (i.e., very preterm) [2]. In 2008, deliveries at 32-33, 34-36 and $37-38$ weeks accounted for $1.2 \%, 7.5 \%$ and $29.7 \%$, respectively, of all births in the United Status. Currently, MPT infants born at 32-33 weeks' gestation and LPT infants born at 34-36 weeks' gestation make up the largest subgroup of preterm (PT) infants and contribute to more than $80 \%$ of premature births in the United States [3]. A growing numbers of reports state that both MPT and LPT infants are at increased risk of neonatal and post discharge morbidity [4]. Infants delivered at these gestational ages are at considerably increased risk of mortality as well as respiratory and non-respiratory morbidity. Equally, there is evidence that these infants may be at increased risk of long-term neurocognitive and behavioural problems and reduced school performance.

Mortality and neonatal morbidity rates in late preterm births are substantial. Compared with infants born at term, preterm infants have higher rates of temperature instability, respiratory distress, apnoea, hypoglycemia, seizures, jaundice, kernicterus, feeding difficulties, periventricular leukomalacia and rehospitalisation [5]. White matter (WM) brain injuries are a characteristic of preterm infants [6,7] Periventricular leukomalacia (PVL) is the predominant form of white matter brain injuries, and it is one of the principal causes of cerebral palsy in preterm infants. Five to ten percent of preterm survivors showed permanent motor impairment, including cerebral palsy and $50 \%$ showed cognitive impairments at school age; attention, language, hearing, vision and learning disabilities were frequently observed $[8,9]$.

The etiology of white matter brain injury is multifactorial; hypoxia, ischemia, infection and inflammation are considered to be the main causes.
Therefore, it is very important to develop procedures that may decrease WM lesion sequels in new-borns that present prenatal and perinatal risk factors for brain damage [10]. Risk factors have also been related to cortical volume reductions [11]. This work describes the outcome of early neurohabilitation therapy applied to new-borns with several risk factors for brain damage and whose MRI scans detected brain lesions [12-14].

\section{Methods}

The Ethics Committee of the Instituto de Neurobiología of the Universidad Nacional Autónoma de México approved this study, which also complies with the Ethical Principles for Medical Research Involving Human Subjects established by the Helsinki Declaration. Informed written parental consent for participation in this study was obtained for all subjects.

\section{Participants}

A total of 262 infants with risk factors for brain damage were studied.

\section{Inclusion criteria}

A corrected age (CA) of 2 months or less and prenatal and/or perinatal risk factor for brain damage. After the infants were discharged from the hospital where they were born, their parents were invited to participate in a special project of the Unit for Neurodevelopmental Research at the Universidad Nacional Autónoma de México in Queretaro. Two hundred and sixty-two infants were classified according

*Corresponding author: Thalía Harmony, National Autonomous University of Mexico, Institute of Neurobiology, Department of Behavioral and Cognitive Neurobiology, Boulevard Juriquilla 3001, Vacation Specials 76230, Querétaro, Mexico, Tel: 52-442-1926101; Ext. 113; 52-442-3527773; Fax: 524422381005 E-mail: thaliah@unam.mx

Received June 14, 2017; Accepted June 28, 2017; Published July 05, 2017

Citation: Harmony T (2017) Outcome of Infants at Risk of Brain Damage after Katona Neurohabilitation Therapy. Int J Neurorehabilitation 4: 277. doi: 10.4172/2376-0281.1000277

Copyright: () 2017 Harmony T. This is an open-access article distributed unde the terms of the Creative Commons Attribution License, which permits unrestricted use, distribution, and reproduction in any medium, provided the original author and source are credited. 
to the weeks of gestational age (GA). Table 1 shows the number of infants per group as well as their gender and mean weight at birth.

\section{Exclusion criteria}

Presence of genetic factors associated with brain damage, cardiovascular pathology, brain malformations and/or chromosomal aberrations.

\section{Evaluation}

A) Clinical paediatric and neuropediatric examinations [15]. B) Bayley Scales of Infant and Toddler II (BSID-II) was used and both the Mental Development Index (MDI) and the Psychomotor Development Index (PDI) were recorded. MDI measures environmental responsiveness, sensory and perceptual abilities, memory, learning and early language and communication abilities; PDI measures both gross and fine motor skills. MDI and PDI scores $\geq 85$ are considered normal; values between 70 and 84 indicate a mildly delayed performance and scores $\leq 69$ indicate a significantly delayed performance [16]. C) Magnetic resonance imaging (MRI) using 1.0 T Philips equipment and a 3.0 T GE. D) Katona evaluations [12-14]. All these evaluations were repeated according to a time schedule. Neuropediatric evaluations were conducted every month during the first year, every 3 months during the second year, and every 6 months after the third year. Bailey-II evaluations and MRI scans were done at program entry, every 4 months during the first year and every 6 months during the second and third year.

\section{Evaluation and treatment (Neurohabilitation)}

Neurohabilitation is the name that Katona suggested for this methodology. It is a diagnostic and therapeutic methodology that should begin before a corrected age of 3 months. The evaluation is carried out with some of the manoeuvres used in the therapy itself, and it measures the following parameters: muscle tone (passive and active); hemi body

\begin{tabular}{|c|c|c|c|c|c|c|c|c|}
\hline \multirow{4}{*}{$\begin{array}{c}\text { Group } \\
\text { GA } \\
25-27(n=17)\end{array}$} & \multicolumn{4}{|c|}{ Gender } & \multicolumn{2}{|c|}{ Weight (g) } & \multirow{3}{*}{\multicolumn{2}{|c|}{$\begin{array}{c}\text { Weight } \\
\text { Range (g) }\end{array}$}} \\
\hline & \multicolumn{2}{|c|}{$F$} & \multicolumn{2}{|c|}{ M } & \multirow{3}{*}{$\begin{array}{c}\mathbf{X} \\
1043\end{array}$} & \multirow{3}{*}{$\begin{array}{l}\text { SD } \\
381\end{array}$} & & \\
\hline & \multirow{2}{*}{$\begin{array}{c}\mathbf{N} \\
10\end{array}$} & \multirow{2}{*}{$\begin{array}{c}\% \\
59 \% \\
\end{array}$} & \multirow{2}{*}{$\frac{\mathbf{N}}{7}$} & \multirow{2}{*}{$\begin{array}{c}\% \\
41 \%\end{array}$} & & & & \\
\hline & & & & & & & 700 & 2200 \\
\hline $28-29(n=37)$ & 12 & $32 \%$ & 25 & $68 \%$ & 1153 & 275 & 675 & 1680 \\
\hline $30-31(\mathrm{~N}=36)$ & 17 & $47 \%$ & 19 & $53 \%$ & 1480 & 321 & 920 & 2100 \\
\hline $32-34(\mathrm{~N}=60)$ & 27 & $45 \%$ & 33 & $55 \%$ & 1851 & 396 & 1000 & 2850 \\
\hline $35-36(N=53)$ & 18 & $34 \%$ & 35 & $66 \%$ & 2383 & 478 & 1450 & 3430 \\
\hline $37-38(\mathrm{~N}=35)$ & 20 & $57 \%$ & 15 & $43 \%$ & 2940 & 449 & 1875 & 2125 \\
\hline $39-40(n=24)$ & 9 & $37 \%$ & 15 & $63 \%$ & 3196 & 540 & 1500 & 4300 \\
\hline Total $(\mathrm{N}=262)$ & 113 & $43 \%$ & 149 & $57 \%$ & & & & \\
\hline
\end{tabular}

Table 1: Gender and birth weight. symmetry throughout manoeuvre performance; attention, eye tracking, and auditory monitoring; and neurological signs of alarm (thumb in fist, scissor gait, strabismus, irritability, axial hyperextension, among others).

The therapeutic procedure is based on early integrated complex movements such as chains of processes in which the neck, trunk and extremities perform complex and continual movements in certain repetitive patterns. Katona described them as 'elementary neuromotor patterns', which are divided into two groups: those directed to body verticalization and those directed to locomotion. These movements are triggered by different head positions that stimulate the vestibular nuclei. These nuclei have developing descendent projections to the spinal cord and ascending projections to several nuclei of the brain stem, thalamus, cerebellum, and basal ganglia. At the same time, movements generate activation of different receptors that send afferent impulses to the sensorimotor cortex. This constant feedback helps in the organization of motor control.

At the beginning of the treatment, therapists conducted the neurohabilitation evaluation to obtain information required to program the exercises that parents were going to learn to perform at home. Monthly evaluations were programmed to change the exercises that parents were to apply at home. The treatment consisted in 3 to 4 sessions of personalized training in elementary patterns lasting 45 minutes per day. Each session consisted in repeating 6 to 9 different sensorimotor patterns between 4 and 5 times. The exit of the therapy completion depended on the intensity and accuracy that was applied.

Parents were required go to the therapist on a daily basis during the first 3 months for supervision. Afterwards, the therapist indicated how often the parents should visit and also how the therapy sessions were going to be integrated into the infant's sleep-wake schedule and feeding and nursing times.

Every month, motor performance and visual and auditory attention was examined, as well as the ages at which the infant mastered various developmental milestones.

\section{Results}

Table 1 shows the number and percentage of infants in all seven groups according to gestational age. The majority of infants were born at 32-34 and 35-36 weeks of GA. The percentage of male infants was greater than the percentage of female infants, except in the 25-27 and 37-38 week groups. Mean birth weight increased with GA as expected. The minimum birth weight revealed that groups with infants who had a GA between 25 and 36 weeks had at least one subject with a birth weight of less than $1500 \mathrm{~g}$ (very low birth weight, VLWB).

Table 2 illustrates the percentage of infants in each group with

\begin{tabular}{|c|c|c|c|c|c|c|c|c|c|c|c|c|c|c|c|c|c|c|c|c|c|c|c|c|c|c|c|}
\hline \multirow{2}{*}{$\begin{array}{c}\text { Factor } \\
\text { Group (GA) }\end{array}$} & \multicolumn{2}{|c|}{ Abortions } & \multicolumn{2}{|c|}{$\begin{array}{c}\text { Maternal } \\
\text { Infections }\end{array}$} & \multicolumn{2}{|c|}{ Toxemia } & \multicolumn{2}{|c|}{$\begin{array}{c}\text { Acute fetal } \\
\text { distress }\end{array}$} & \multicolumn{2}{|c|}{$\begin{array}{c}\text { Very Low } \\
\text { birth weight }\end{array}$} & \multicolumn{2}{|c|}{ Apgar $<7$} & \multicolumn{2}{|c|}{ Asphyxia } & \multicolumn{2}{|c|}{$\mathrm{O2}$} & \multicolumn{2}{|c|}{ Sepsis } & \multicolumn{2}{|c|}{ HIC } & \multicolumn{2}{|c|}{ Seizures } & \multicolumn{2}{|c|}{$\begin{array}{l}\text { Hyperbili- } \\
\text { rubinemia }\end{array}$} & \multicolumn{2}{|c|}{$\begin{array}{l}\text { Metabolic } \\
\text { Problems }\end{array}$} & \multirow{2}{*}{$\begin{array}{l}\text { Number of } \\
\text { factors per } \\
\text { infant }\end{array}$} \\
\hline & $\mathbf{N}$ & $\%^{*}$ & $\mathbf{N}$ & $\% *$ & $\mathbf{N}$ & $\%^{*}$ & $\mathbf{N}$ & $\%^{*}$ & $\mathbf{N}$ & $\%^{*}$ & $\mathbf{N}$ & $\%^{*}$ & $\mathbf{N}$ & \%* & $\mathbf{N}$ & \%* & $\mathbf{N}$ & $\%^{*}$ & $\mathbf{N}$ & $\%^{*}$ & $\mathbf{N}$ & $\%^{*}$ & $\mathbf{N}$ & \%* & $\mathbf{N}$ & $\%^{*}$ & \\
\hline $25-27(n=17)$ & 3 & 18 & $s$ & 53 & 4 & 24 & 2 & 6 & 11 & 6 & 6 & 35 & 12 & & 7 & 41 & 12 & 70 & 4 & 24 & 4 & 24 & 9 & 53 & 11 & 65 & $78 / 17=4.6$ \\
\hline $28-29(n=37)$ & 6 & 16 & 14 & 38 & 14 & 38 & 8 & 22 & 21 & 57 & 10 & 27 & 14 & 38 & 18 & 49 & 27 & 73 & 8 & 22 & 8 & 22 & 27 & 73 & 30 & 81 & $171 / 37=4.6$ \\
\hline $30-31(\mathrm{~N}=36)$ & 9 & 25 & 16 & 44 & 21 & 58 & 2 & 6 & 21 & 5 & 4 & 11 & 13 & 36 & 22 & 61 & 29 & 81 & 4 & 11 & 3 & 3 & 30 & 83 & 22 & 61 & $150 / 36=4.2$ \\
\hline $32-34(\mathrm{~N}=60)$ & 8 & 13 & 4 & 68 & 25 & 42 & 11 & 18 & 36 & 60 & 9 & 15 & 26 & 43 & 44 & 73 & 47 & 78 & 8 & 14 & 4 & 7 & 2 & 86 & 34 & 57 & $271 / 60=4.5$ \\
\hline $35-36(\mathrm{~N}=53)$ & 6 & 11 & 29 & 55 & 15 & 28 & 10 & 19 & 11 & 21 & 5 & 9 & 17 & 32 & 20 & 38 & 26 & 49 & 1 & 2 & 7 & 13 & 32 & 60 & 18 & 34 & $147 / 53=2.8$ \\
\hline $37-38(\mathrm{~N}=35)$ & 6 & 17 & $1 \varepsilon$ & 51 & 7 & 20 & 15 & 43 & 6 & 17 & 12 & 34 & 15 & 43 & 11 & 31 & 9 & 26 & 3 & 9 & 5 & 14 & 22 & 63 & 11 & 31 & $109 / 35=3.1$ \\
\hline $39-40(n=24)$ & 5 & 21 & 11 & 46 & 4 & 17 & 5 & 21 & 1 & 4 & 4 & 17 & 8 & 33 & 6 & 25 & 7 & 29 & 0 & 0 & 4 & 17 & 13 & 54 & 9 & 38 & $57 / 24=2.4$ \\
\hline Total $\mathrm{N}=262$ & 43 & 19 & 138 & 53 & 90 & 34 & 53 & 20 & 128 & 49 & 50 & 19 & 50 & 19 & 128 & 49 & 157 & 60 & 28 & 11 & 35 & 13 & 185 & 71 & 135 & 52 & $983 / 262=3.8$ \\
\hline
\end{tabular}

* \% has been calculated in relation to the number of patients in each group. As each infant may have more than one risk factor, the sum is higher than $100 \%$ Yate's Chi square $=68.639$ degrees of freedom $=54 p$ value $=0.086$

Table 2: Risk factors for each group. 
the risk factors detected by the team of clinicians (gynaecologists, neonatologists and neuropediatricians). Several risk factors were identified in each infant. There were no significant differences between groups regarding the incidence of different risk factors. However, the most frequent risk factors found in the sample of 262 infants were maternal infections, sepsis, hyperbilirubinemia and metabolic problems.

Table 3 shows the number and percentage of infants whose MRI scans displayed abnormal findings. The first 4 columns describe the increase in left and right ventricle volumes and in the subarachnoid space. These increases are more than 2 standard deviations above the mean of a group of normal infants of the same age obtained in the same equipment (Bosch, in preparation). The corpus callosum (CC) volume was also measured in the group of normal infants, and the decreases in the CC volumes shown in Table 3 are more than 2 standard deviations below the mean of the normal subjects (Bosch, in preparation). One infant may have more than one abnormal finding. Almost half (46\%) of the infants show an abnormal increase in (left and/or right) ventricle volumes. Diffuse PVL was diagnosed in $8 \%$ of the infants and was predominantly observed in the extremely preterm infant groups. Cystic PVL was detected in 10 infants with a GA between 32 and 36 weeks. Predominantly at the same age, T2-weighted diffuse excessive high signal intensity and haemorrhages were observed. Infarcts were more frequently observed in groups with higher GA. Normal MRI was present in all the groups and did not exceed $23 \%$ of infants.

All infants received Katona's neurohabilitation treatment and follow-up as described in Methods. The Bayley-II scale was used to measure infant outcomes (Table 4). The 37-38 week GA group had the best outcome. However, a greater number of infants had normal results in the PDI than in the MDI. This was more notorious in the extremely preterm (GA 25-29) and term (GA 39-40) infants.

\section{Discussion}

\section{Risk factors}

We considered the presence of risk factors for brain damage to select our sample. The most frequently observed risk factors in all groups were maternal infections, low birth weight, Apgar $<7$ at 5 min, sepsis, hyperbilirubinemia and metabolic problems. No significant differences in the presence of risk factors between groups were observed. It is important to detect risk factors, such as maternal infections and fetal growth restriction, during pregnancy to provide adequate treatment and

\begin{tabular}{|c|c|c|c|c|c|c|c|c|c|c|c|c|c|c|c|c|c|c|c|c|c|c|c|c|c|c|}
\hline \multirow{2}{*}{$\begin{array}{l}\text { MRI } \\
\text { GA }\end{array}$} & \multicolumn{2}{|c|}{$\uparrow \mathbf{L V}$} & \multicolumn{2}{|c|}{$\uparrow \mathbf{L L V}$} & \multicolumn{2}{|c|}{$\uparrow \mathbf{R L V}$} & \multicolumn{2}{|c|}{$\uparrow$ SS } & \multicolumn{2}{|c|}{$\downarrow \mathbf{C C}$} & \multicolumn{2}{|c|}{ DWMA } & \multicolumn{2}{|c|}{ Cystic PVL } & \multicolumn{2}{|c|}{ Haemorrhagias } & \multicolumn{2}{|c|}{$\downarrow$ Cerebell } & \multicolumn{2}{|c|}{$\downarrow$ Cortex } & \multicolumn{2}{|c|}{$\uparrow$ 3rd Vent } & \multicolumn{2}{|c|}{ Infarct } & \multicolumn{2}{|c|}{ Normal } \\
\hline & $\mathrm{N}$ & $\%$ & $N$ & $\%$ & $N$ & $\%$ & $\mathrm{~N}$ & $\%$ & $\mathrm{~N}$ & $\%$ & $\mathrm{~N}$ & $\%$ & $\mathrm{~N}$ & $\%$ & $\mathrm{~N}$ & $\%$ & $\mathrm{~N}$ & $\%$ & $\mathrm{~N}$ & $\%$ & $\mathrm{~N}$ & $\%$ & $\mathrm{~N}$ & $\%$ & $\mathrm{~N}$ & $\%$ \\
\hline $25-27(\mathrm{~N}=17)$ & 3 & 18 & 10 & 65 & 1 & 6 & 1 & 6 & 2 & 12 & 4 & 24 & 0 & 0 & 1 & 6 & 0 & 0 & 0 & 0 & 0 & 0 & 0 & 0 & 3 & 18 \\
\hline $28-29(\mathrm{~N}=37)$ & 8 & 22 & 2 & 5 & 0 & 0 & 10 & 27 & 6 & 16 & 5 & 13 & 0 & 0 & 1 & 3 & 0 & 0 & 1 & 3 & 2 & 5 & 1 & 3 & 5 & 14 \\
\hline $30-31(\mathrm{~N}=36)$ & 8 & 22 & 1 & 3 & 1 & 3 & 14 & 39 & 3 & 9 & 4 & 11 & 0 & 0 & 1 & 3 & 1 & 3 & 1 & 3 & 0 & 0 & 1 & 3 & 3 & 8 \\
\hline $32-34(\mathrm{~N}=60)$ & 18 & 30 & 10 & 17 & 5 & 8 & 16 & 27 & 11 & 18 & 5 & 8 & 5 & 8 & 4 & 7 & 0 & 0 & 2 & 4 & 0 & 0 & 1 & 2 & 10 & 17 \\
\hline $35-36(\mathrm{~N}=53)$ & 12 & 23 & 5 & 9 & 2 & 4 & 15 & 28 & 13 & 24 & 5 & 9 & 5 & 9 & 3 & 6 & 0 & 0 & 2 & 4 & 1 & 2 & 0 & 0 & 12 & 23 \\
\hline $37-38(\mathrm{~N}=35)$ & 12 & 34 & 3 & 9 & 2 & 6 & 16 & 46 & 8 & 22 & 2 & 6 & 0 & 0 & 2 & 6 & 2 & 6 & 0 & 0 & 2 & 6 & 4 & 11 & 5 & 14 \\
\hline $39-40(\mathrm{~N}=24)$ & 7 & 29 & 5 & 21 & 4 & 17 & 13 & 54 & 5 & 21 & 1 & 4 & 0 & 0 & 0 & 0 & 0 & 0 & 2 & 8 & 0 & 0 & 2 & 8 & 4 & 17 \\
\hline Total $(\mathrm{N}=262)$ & 68 & 26 & 36 & 14 & 15 & 6 & 85 & 32 & 52 & 19 & 22 & 8 & 10 & 4 & 12 & 5 & 3 & 1 & 8 & 3 & 5 & 2 & 9 & 3 & 42 & 16 \\
\hline
\end{tabular}

LV: Both Ventricles; SS: Subarachnoidal Space; LLV: Left Ventricle; CC: Corpus Callosum; RV: Right Ventricle; DWMA: Diffuse White Matter Abnormalities

Table 3: MRI findings in each group.

\begin{tabular}{|c|c|c|c|c|c|c|c|c|c|c|}
\hline \multicolumn{11}{|c|}{ Bayley II: Mental Development Index } \\
\hline \multirow[t]{2}{*}{ GA } & \multicolumn{2}{|c|}{ Normal } & \multicolumn{2}{|c|}{ Accelerated } & \multicolumn{2}{|c|}{ Mildly Delayed } & \multicolumn{2}{|c|}{ Significantly Delayed } & \multicolumn{2}{|c|}{ Total } \\
\hline & $\mathbf{N}$ & $\%$ & $\mathbf{N}$ & $\%$ & $\mathbf{N}$ & $\%$ & $\mathbf{N}$ & $\%$ & $\mathbf{N}$ & $\%$ \\
\hline $25-27$ & 7 & 41 & 1 & 6 & 6 & 35 & 3 & 18 & 17 & 100 \\
\hline $28-29$ & 14 & 38 & 2 & 5 & 13 & 35 & 8 & 22 & 37 & 100 \\
\hline $30-31$ & 25 & 69 & 1 & 3 & 7 & 20 & 3 & 8 & 36 & 100 \\
\hline $32-34$ & 37 & 62 & 8 & 13 & 11 & 18 & 4 & 7 & 60 & 100 \\
\hline $35-36$ & 33 & 62 & 3 & 6 & 9 & 17 & 8 & 15 & 53 & 100 \\
\hline $37-38$ & 28 & 80 & 2 & 6 & 3 & 8 & 2 & 6 & 35 & 100 \\
\hline $39-40$ & 16 & 67 & 1 & 4 & 6 & 25 & 1 & 4 & 24 & 100 \\
\hline Total & 160 & 61 & 18 & 7 & 55 & 21 & 29 & 11 & 262 & 100 \\
\hline \multicolumn{11}{|c|}{ Bayley II: Psychomotor Development Index } \\
\hline \multirow[t]{2}{*}{ GA } & \multicolumn{2}{|c|}{ Normal } & \multicolumn{2}{|c|}{ Accelerated } & \multicolumn{2}{|c|}{ Mildly Delayed } & \multicolumn{2}{|c|}{ Significantly Delayed } & \multicolumn{2}{|c|}{ Total } \\
\hline & $\mathbf{N}$ & $\%$ & $\mathbf{N}$ & $\%$ & $\mathbf{N}$ & $\%$ & $\mathbf{N}$ & $\%$ & $\mathbf{N}$ & $\%$ \\
\hline $25-27$ & 10 & 60 & 3 & 18 & 0 & 0 & 4 & 24 & 17 & 100 \\
\hline $28-29$ & 22 & 59 & 0 & 0 & 7 & 19 & 8 & 22 & 37 & 100 \\
\hline $30-31$ & 24 & 67 & 1 & 3 & 10 & 28 & 1 & 3 & 36 & 100 \\
\hline $32-34$ & 42 & 70 & 7 & 11 & 4 & 7 & 7 & 12 & 60 & 100 \\
\hline $35-36$ & 44 & 83 & 2 & 3 & 4 & 8 & 3 & 6 & 53 & 100 \\
\hline $37-38$ & 26 & 74 & 5 & 14 & 3 & 9 & 1 & 3 & 35 & 100 \\
\hline $39-40$ & 22 & 92 & 1 & 4 & 0 & 0 & 1 & 4 & 24 & 100 \\
\hline Total & 190 & 73 & 19 & 7 & 28 & 11 & 24 & 9 & 262 & 100 \\
\hline
\end{tabular}

Table 4: Outcome of infants with risk factors for brain damage. 
follow-up. Furthermore, prevention of neonatal infections should be a continuous priority in maternal hospitals. More than half of all infants admitted to a neonatal intensive care unit (NICU) have developed or are at risk of developing sepsis [17].

\section{MRI}

The MRI findings in our sample demonstrated clear brain lesions in many infants. Diffuse and cystic periventricular leukomalacia, intraventricular haemorrhages, cerebral infarcts, cerebral cortex and cerebellar atrophies and T2-weighted diffuse WM abnormalities are pathologies related to poor neurodevelopmental outcomes $[18,19]$. The association between neonatal brain volumes and later neurodevelopmental outcomes has been explored in a few studies. In relation to the MRI findings, white matter abnormalities (WMA) are the most common pathologies reported with conventional MRI scans in preterm infants; for instance, cystic lesions, punctuate lesions, delayed myelination, volume loss, thinning of the corpus callosum and T2weighted diffuse WM abnormalities [20]. White matter injury (WMI) is also observed in term infants [21]. Our observations are in agreement with these descriptions. Abnormal increases in lateral ventricle volumes were observed in $46 \%$ of the infants. This finding and the thinning of the corpus callosum in preterm infants are in accordance with previous descriptions [20] and are directly related to white matter injury [19,21]. When the increase in lateral ventricle volume was unilateral, the left ventricle was predominantly affected. Such preference could be associated with language problems observed later in infancy.

Grey matter abnormalities have also been described. Inder et al. [20] found that very preterm infants with moderate-to-severe disability at 12 months of age (based on clinical examination) had reduced cortical and subcortical grey matter volumes and increased cerebrospinal fluid volumes compared to infants without disability or with mild disability. Enlarged extracerebral space is a relatively common abnormal finding [20]. Anderson et al. [19] described that in the 1998-2000 Christchurch cohort, $51 \%$ of very preterm infants had a mild enlargement of the extracerebral space, while an additional $17 \%$ had a moderate-to-severe enlargement. As mentioned in the results, enlarged extracerebral space was also observed in all the groups of our sample, especially those with infants who had a GA of 37-38 or 39-40 weeks. These enlargements were more than 2 standard deviations (SD) of the mean according to the norms for the age at which the MRI was acquired (Bosch, in preparation). Grey matter abnormalities in our sample were also observed in accordance with previous reports [22,23].

A meta-analysis of 20 papers describing the predictive value of 3 different MRI findings at term such as white matter abnormality (WMA), brain abnormality (BA) and/or diffuse excessive high signal intensity (DEHSI) concluded that pooled sensitivity and specificity values for $\mathrm{CP}$ prediction were $77 \%$ and $79 \%$, respectively. For prediction of motor function were $72 \%$ and $62 \%$, respectively. Lower values were found for prediction of other abnormal functions as visual and/or hearing problems, and neurocognitive and behavioural deficits [24].

It is well known that brain abnormalities observed in conventional structural MRI scans in the neonatal period are related to early neurodevelopmental impairments; therefore, our sample, which showed the same previously reported abnormalities, may be considered as a sample of neonates with brain damage and that could show neurodevelopmental deficits in their outcome.

\section{Outcome}

Psychomotor development of preterm infants depends on gestational age; moreover, the risks of medical and social disabilities in adulthood increase with decreasing gestational age at birth [25]. This was observed in our sample. Very preterm infants had a higher percentage of significant delay than the other preterm infants. According to Volpe [18], encephalopathy is important in very low birth weight preterm infants as $25-50 \%$ present subsequent cognitive, behavioural, attentional, or socialization deficits and 5-10\%. Major motor deficits (e.g. cerebral palsy). In a Dutch sample of infants with a GA of less than 32 weeks, the outcome at 18 and 24 months of corrected age showed that $40 \%$ of the very prematurely born children had both delayed mental and/or psychomotor development. However, no pathology was referred in these children [26]. Similarly, in another neurological study, $78 \%$ and $75 \%$ of preterm infants ( $<32$ weeks) in its sample showed normal results at the 1- and 2-years follow-ups, respectively. BayleyII scales were normal in $68 \%$ and $72 \%$ of infants, mildly abnormal in $24 \%$ and $21 \%$ and severely abnormal in $8 \%$ and $7 \%$ [27]. However, no pathology was referred in these children.

A study conducted in Norway on the prevalence of sequelae according to GA discovered that out of 1822 infants that were born before or at 34 weeks of GA, the incidence of cerebral palsy was $17 \%$, mental retardation was $7.2 \%$ and sensory disabilities was $6.8 \%$ [25]. Kaaresen et al. [28] reported that in a control group of 67 preterm infants who weighed less than 2,000 $\mathrm{g}$ at birth, the outcome measured by the Bayley-II scale at 2 years old showed that $12 \%$ had a significant delay and $16 \%$ had a mild delay in their MDI. In same group of children, $5 \%$ had a severe delay and $12 \%$ had a mild delay in their PDI. Although no reference of brain pathology was given in this report, it shows that more children had a delay in the MDI evaluation than in the PDI evaluation. The same happened in our sample.

In a study [8], that looked for specific outcomes such as moderate/ severe mental retardation, sensorineural hearing loss/blindness, cerebral palsy, and epilepsy in infants with different weights at birth, the author concluded that $6-8 \%$ of infants with these outcomes had low birth weight $(<2500 \mathrm{~g}), 14-17 \%$ had very low birth weight $(<1500 \mathrm{~g})$ and over $50 \%$ required special education.

It is very difficult to compare our results because most of the references did not report the presence of brain damage; they only described GA and birth weight. However, in a group of 23 high-risk low birth weight infants on which 15 has PVL, 5 intraventricular haemorrhage and 3 both findings were divided in two groups, one control and the other treated with an early intervention program. In the control group, $73 \%$ of the infants showed an abnormal neurological exam, with MDI mean and SD values of $67.9 \pm 15.1$ and the PDI with a mean value of $63.1 \pm 13$.6. Treated infants showed no significant differences with the control group; $83 \%$ had abnormal results in their neurological examination, a mean MDI of $76.4 \pm 15.4$ and a mean PDI of $69.8 \pm 19.2$ [29].

We selected a sample of 262 infants with risk factors for brain damage. White matter and grey matter injuries were observed in the MRI evaluations of $84 \%$ of the infants. Our work is not a clinical control trial since previous studies have shown the efficacy of neurohabilitation; ethical considerations and the Helsinki Declaration prohibit a control sample with the same type of evaluations across time as those used for the treated group but without treatment. Harmony et al. [14] reported that the outcome at 6-7 years of children with brain damage who received neurohabilitation beginning at 2 months of age had significant more children with a normal outcome than a control group on which treatment was voluntarily discontinued after the initial evaluation. Katona's statistics [30] on neurohabilitation applied to 2,189 infants (less than 6 months old) with suspected perinatal brain damage showed 
that, at a corrected age of 18 months, $46 \%$ had a normal outcome, $32 \%$ improved relative to their initial symptoms, and $22 \%$ had no change or their symptoms had become worse.

In this work we treated infants with brain damage and different GAs. The results in very preterm infants ( $G A=25-27,28-29$ weeks) showed that more than $40 \%$ reached a normal outcome in the MDI and over $69 \%$ also reached a normal outcome in the PDI; a very low percentage of infants with a GA $>31$ weeks had a significantly delayed outcome in the MDI and PDI. MDI values were lower than PDI values at all ages. The remaining infants, with the exception of very low term infants, had very low percentages of significantly delayed outcomes in the PDI. Over $80 \%$ of infants with a $\mathrm{GA}>31$ weeks had a normal outcome in the PDI.

These results suggest that preterm infants with risk factors and brain damage demonstrated by MRI scans may improve their outcome with early neurohabilitation treatment. We recommend that infants who are discharged from the intensive care unit should follow the early neurohabilitation procedure to improve their outcome. However, this longitudinal study has important limitations, as it only has results for infants up to 24 months of age. The most frequent sequels in preterm infants are in the cognitive domain, and they include attention, language, and learning deficits; therefore, it is mandatory to continue providing these infants with follow-up.

\section{Conclusion}

Risk factors for brain damage are very frequent and should be taken into account for early diagnosis and treatment. All infants in our sample had abnormal results in their clinical examinations and more than $84 \%$ had abnormal MRI findings compatible with white and grey matter injuries that may affect their motor and cognitive neurodevelopment. Neurohabilitation therapy showed a normal outcome in more than $50 \%$ of infants with a $\mathrm{GA}<29$ weeks and in more than $70 \%$ of infants with a GA $\geq 30$ weeks. Therefore, we recommend using neurohabilitation as early as possible after birth to diagnose and treat new-borns at risk of brain damage.

\section{Acknowledgement}

The authors thank Eng. Paulina Alvarez García, Ms. Teresa Alvarez Vázquez, M. In Sc. Leonor Casanova Rico, Psychologist Lourdes Lara Ayala, Ms. Elsa Olivia Ruiz Martínez, Eng. Héctor Belmont Tamayo, Eng. Johnatan Jorge Neyra Nieves for their collaboration They are also very grateful to the parents and children of the sample.

\section{References}

1. Back SA (2014) Cerebral white and gray matter injury in new-borns: New insights into pathophysiology and management. Clin Perinatol 41: 1-24.

2. Blondel B, Lelong N, Kermarrec M, Goffinet F (2011) Trends in perinata health in France from 1995 to 2010 Results from the French National Perinatal Surveys. J Gynecol Obstet Biol Reprod (Paris) 41:151-166.

3. Vohr B (2013) Long-term outcomes of moderately preterm, late preterm and early term infants. Clin Perinatol 40: 739-751.

4. Ananth CV, Friedman AM, Gyamfi-Bannerman C (2013) Epidemiology of moderate preterm, late preterm and early term delivery. Clin Perinatol 40: 601610.

5. Wang ML, Dorer DJ, Fleming MP, Catlin EA (2004) Clinical outcomes of nearterm infants. Pediatrics 114: 372-376.

6. Dyet LE, Kennea N, Counsell SJ, Elia FM, Morenike AO, et al. (2006) Natural history of brain lesions in extremely preterm infants studied with serial magnetic resonance imaging from birth and neurodevelopmental assessment. Pediatrics 118: $536-548$.

7. Kidokoro H, Neil JJ, Inder TE (2013) New MR imaging assessment tool to define brain abnormalities in very preterm infants at term. AJNR Am J Neuroradiol 34: 2208-2214.

8. Aylward GP (2014) Update on neurodevelopmental outcomes of infants born prematurely. J Dev Behav Pediatr 35: 392-393.
9. Delobel-Ayoub M, Arnaud C, White-Koning M, Casper C, Pierrat V, et al. (2009) Behavioral problems and cognitive performance at 5 years of age after very preterm birth: The EPIPAGE Study. Pediatrics 123: 1485-1492.

10. Rees S, Inder TE (2005) Fetal and neonatal origins of altered brain development Early Hum Dev 81: 753-761.

11. Thompson DK, Merilyn B, Simon K, Michael J, Lex W et al. (2007) Perinata risk factors altering regional brain structure in the preterm infant. Brain 130: 667-677.

12. Katona F (1988) Developmental clinical neurology and neurohabilitation in the secondary prevention of pre and perinatal injuries of the brain, In: Vietze PM, Vaughan HG (Eds.), Early Identification of Infants with Developmental Disabilities, Grune and Stratton, Philadelphia, pp: 121-144.

13. Porras-Kattz and Harmony $T$ (2007) Neurorehabilitation: A diagnostic and therapeutic method to prevent brain lesion sequelaes in new-born and infants. Bol Med Hosp Infant Mex 64: 125-135

14. Harmony T, Barrera-Reséndiz J, Juárez-Colín ME, Carrillo-Prado C, PedrazaAguilar MC et al. (2016) Longitudinal study of children with perinatal brain damage in whom early neurohabilitation was applied: Preliminary report. Neurosci Lett 611: 59-67.

15. Amiel-Tison C (2001) Neurología perinatal, Barcelona: Masson S.A.

16. Bayley N (2000) Book review: Bayley scales of infant development, Second edition: Manual. J Psychoeduc Assess 18: 185-195.

17. Sunshine $P(2009)$ Neonatal encephalopathy: Epidemiology and overview. In Philip IN, Stevenson DK, Benitz WE, Sunshine P, Hintz SR, Druzin ML.(Eds). Fetal and Neonatal Brain Injury. 4th edn. New York NY: Cambridge University Press, pp: 1-13.

18. Volpe JJ (2009) Brain injury in premature infants: A complex amalgam of destructive and developmental disturbances. Lancet Neurol 8: 110-124

19. Anderson PJ, Cheong JL, Thompson DK (2015) The predictive validity of neonatal MRI for neurodevelopmental outcome in very preterm children. Semin Perinatol 39: 147-158.

20. Inder TE, Wells SJ, Mogridge NB, Spencer C, Volpe JJ (2003) Defining the nature of the cerebral abnormalities in the premature infant: A qualitative magnetic resonance imaging study. J Pediatr 143: 171-179.

21. Leviton A, Gilles F (1996) Ventriculomegaly, delayed myelination, white matter hypoplasia and "periventricular" leukomalacia: How are they related? Pediatr Neurol 15: 127-136.

22. Horsch S, Hallberg B, Leifsdottir K, Skiöld B, Nagy Z, et al. (2007) Brain abnormalities in extremely low gestational age infants: A Swedish population based MRI study. Acta Paediatr 96: 979-984.

23. Miller SP, Ferriero DM, Leonard C, Piecuch R, Glidden DV, et al. (2005) Early brain injury in premature newborns detected with magnetic resonance imaging is associated with adverse early neurodevelopmental outcome. J Pediatr 147: 609-616.

24. van't Hooft J, van der Lee JH, Opmeer BC, Aarnoudse-Moens $\mathrm{CH}$, Leenders AG, et al. (2015) Predicting developmental outcomes in premature infants by term equivalent MRI: Systematic review and meta-analysis. Syst Rev 4: 71-81.

25. Moster D, Lie RT, Markestad T (2008) Long-term medical and socia consequences of preterm birth. N Engl J Med 359: 262-273.

26. Stoelhorst GM, Rijken M, Martens SE, van Zwieten PH, Feenstra J (2003) Developmental outcome at 18 and 24 months of age in very preterm children: A cohort study from 1996 to 1997. Early Hum Dev 72: 83-95.

27. Maguire CM, Walther FJ, van Zwieten PH, Le Cessie S, Wit JM, et al. (2009) Follow-up outcomes at 1 and 2 years of infants born less than 32 weeks after newborn individualized developmental care and assessment program. Pediatrics 123:1081-1087.

28. Kaaresen PI, Ronning JA, Tunby J, Nordhov SM, Ulvund SE, et al. (2008) A randomized controlled trial of an early intervention program in low birth weight children: Outcome at 2 years. Early Hum Dev 84: 201-209.

29. Ohgi S, Fukuda M, Akiyama T, Gima H (2004) Effect of an early intervention programme on low birth weight infants with cerebral injuries. J Paediatr Child Health 40: 689-695.

30. Katona F (2001) Ontogenesis of the Human Nervous System (in Hungarian) (1st ed), Medicina KonyvkiadóRt, Budapest. 